\title{
Reflections on Modernism in Bangladesh and the abstract artist Kazi Ghiyasuddin
}

\author{
Archishman Sarker \\ PhD research scholar at the School of Arts and Aesthetics, Jawaharlal Nehru University, \\ New Delhi.Email: neelgai@hotmail.com
}

\begin{abstract}
:
This paper is an analysis and anamnesis of the art of the Bangladeshi abstract painter Kazi Ghiyasuddin This paper also explores Bangladeshi Modernism- as an artistic movement in close dialogue with Modernist art emerging from the rest of Bengal and the world at the point of emergence of an international Bangladeshi identity. A close study of his art leads to a contemplation on the syncretism of nature and art (culture) and a manifestation of such through the form of the abstract; while situating the 'artist' at an intersection of lived experiences, artistic perception and politics of expression.
\end{abstract}

Keywords: Modernism, Modernism in Bangladesh, Abstract art, Modernism in South Asia, Art and Nature.

\section{'Any view of things that is not strange is false'- Paul Valéry}

In Western art-history, abstract art was a non-conformist culmination, because it not only challenged the rules and perceptions of painting as an art-form but also altered the very language of painting by using the visuals of shape, form, colour and line to create a work of art which may exist with a certain degree of 'freedom' from visual references in the phenomenological world. In other words, in abstract art we find a departure from 'reality' into an area of non-representation and non-imitation. Through the favouring of immediate sensual reaction over imitating and comprehending through form alongside subjectivity of the artist, we are able to observe the process of becoming of the composition itself. The abstract artist for that matter is so much meditative on subjectivity that he doesn't even consider the composition as an object or an 'image' and is also not concerned about the 'meaning' it produces in the semiotic world, rather it suffices him to say that she/he is just 'playing with the medium' where 'the medium' can denote a universal perspective i.e., art itself. A historical understanding of the coming of the abstract art in the West equips us to unravel the ahistorical mysticism of the pure abstract. Beginning from the late nineteenth century, early signs of this new art started becoming visible- starting with the Romanticism-inspired James McNeill Whistler ${ }^{i}$. Whistler was overlooked after the coming of the Impressionists ${ }^{\mathrm{ii}}$. The transition from painting as an object to and as distinct from painting as an 'objective interest in what is seen' was marked by masters such as J M W Turner and Camille Corot and also by the Impressionists who continued the plein air painting of the Barbizon school and then coming with the Expressionists, subject-matter only came to signify or stand for psychological states of being ${ }^{\text {iii }}$. Post-Impressionism and its notable practitioners Paul Gauguin,

\footnotetext{
(C) AesthetixMS 2018. This Open Access article is published under a Creative Commons Attribution Non-Commercial 4.0 International License (http://creativecommons.org/licenses/by-nc/4.0/), which permits non-commercial re-use, distribution, and reproduction in any medium, provided the original work is properly cited. For citation use the DOI. For commercial re-use, please contact editor@chitrolekha.com
} 
Georges Seurat, Vincent Van Gogh and Paul Cézanne also had a phenomenal impact on twentieth century art and which led to the advent of twentieth century abstraction. Cubism which privileged the subject-matter (to make a logical construction of reality based on a view from a single point, with modulated colours in flat areas) along with Fauvism became the art movements that paved the way for the development of abstraction in the twentieth century. In a wide spectrum of views, the post-Jungians would see the emerging abstract art movement as a certain kind of practice of philosophy in the line of the Existentialists and the Anarchists while for Adorno, abstraction was a response to and a reflection of the growing abstraction of social relations in an industrial and subsequently post-Industrial society of the Western hemisphere. However, both the notions are deeply historical when we see the abstract as a human possibility, and thus it to be reduced to social relationships and politics would be to circumscribe it vitality. In the United States in the thirties, forties and till the early fifties- the artistic scene was dominated by abstraction, Surrealism and Dada, following the migration of many artists from Nazi Europe. Those were dynamic and intense times; exploring every formal and political possibility and then transcending both form and politics became the causa prima for the emergence of the late-twentieth century abstract. The Abstract Expressionists and the New York School were notable, and the transformations of painting as an art-form and the activity of painting into 'truly modern' started, and it indeed is a never-ending process.

Twentieth-century European Modernist movements no doubt influenced art practices in the Indian subcontinent. Modernist sensibilities had already started pervading the artistic ethos in pre-Independence India around that time. By the time the Modernist painter Kazi Ghiyasuddin from Bangladesh began his art-practice, Modernist art in the subcontinent had already experienced steady growth, assimilation and evolution. He was born in 1951 in Madaripur, Dhaka Division, Bangladesh. He didn't experience the Partition physically, nor did he had to face migration as many of his artistic predecessors and practitioners of modern art had to. Nonetheless, the impact and devastation of the Partition was all around him. He graduated with a B.F.A. from the then College of Arts and Crafts (now the Faculty of Fine Arts, Dhaka University) in 1970 and then subsequently an M.F.A. from Chittagong University in 1972. He was 'first foreign student' first at Geidai (the Tokyo National University of Liberal Arts) when he arrived in Japan from Bangladesh in 1975 as a Monbusho scholar to pursue a second M.F.A. and then at the Tokyo National University of Fine Arts and Music from where he obtained his doctoral degree in 1985. It must also be remembered at this point the vital role that the domestic institutions, in addition to the Japanese ones, played in 'making' the artist Kazi Ghiyasuddin. The partition of Bengal denied him the chance to study in the metropolis Calcutta and its Govt. Art College which was the alma mater of many of his preceding colleagues. Educational infrastructure post-1947 in East Pakistan was initially in a dwindling state, more so for art education and art-practice. By the time he was a young man and started his higher education, the region was once again affected massively in all spheres of life during the political unrest of the late 6os. However, this institutional, infrastructural and political jeopardy was compensated to some extents in his case, through a scholarship to Japan.

His watercolours fascinated the Japanese art-consumers and connoisseurs and he got inspired to work more in watercolour; he had had more than over forty solo exhibitions in Japan ${ }^{\text {iv }}$. Just before an exhibition in May 2004, the following appeared in the Japan Times- "Ghiyasuddin's watercolours are ethereal yet intense, an effect he achieves by applying up to five layers of colour, thus preserving the almost magical insubstantiality of the medium while creating powerful pigmentation. The oils in this latest series are likewise layered, with the artist returning to the works intermittently over the course of two or more years. They follow the same proportions as 
the watercolours, and have the same titles- but there the resemblance ends." He has a particular attachment for the medium of watercolour, though he works proficiently in both oil and water. His paintings, like all abstract art in general, is a contemplation on form along with a stylistic dialogue with the forces of history and economy- poverty, food shortage, rustic Bengal, Bangladeshi nationalist identity, political instability and Diaspora- all come together in this culmination of style; as 'any style involves first of all the artist's connection to his or her own time, or historical period, society, and antecedents; the aesthetic work, for all its irreducible individuality, is nevertheless a part- or, paradoxically, not a part- of the era in which it was produced and appeared. This is not simply a matter of sociological or political synchrony but more interestingly has to do with rhetorical or formal style' (Said 2006). The musical qualities to his paintings are also the markers of this repertoire of style. Ghiyasuddin in his own words 'try[s] to compose melodies through painting' i.e., consciously he equips his paintings with synesthetic attributes, which is the very crux of his style; based on lyrical expressions of colour, his painting style itself evolved like a musical ensemble- with the evolution of distinct subtle lines and natural shapes. This evolution is central to his artistic career and his affair with Japan which did not hinder his artistic growth but rather assisted it in a very holistic manner, the metropolis of Tokyo could not consume the artist, it helped him evolve and become stronger and richer in spirit, as a certain critic notes- 'If I can take the liberty of commenting on what I believe to be the most striking characteristic of this artist, it would have to be that he has continued to work relentlessly on his painting, genuinely reaching into himself, in obedience to his own sensibilities, despite Tokyo's urbane context of plentiful stimuli and information overload (Miki)' (Falvo 2011).

\section{Bangladeshi Modernism: Roots and Shoots}

According to Professor Lala Rukh Selim of the Department of Sculpture, University of Dhaka, the four pioneers of Bangladeshi Modernism were S M Sultan, Zainul Abedin, Saifuddin Ahmed and Quamrul Hassan (Selim 2014). All of them were at a point of time students of Government College of Art in Calcutta at a time when the influence of Mukul Chandra Dey as its principal was vivid as he had on a regular basis de-emphasized the mere copying of Old Masters as was the trend in academic painting and sought to move beyond just Indian mythological, historical and allegorical subjects (as was the familiarity in the Bengal School) and students were encouraged to paint from their own experiences. Such an approach no doubt marked an anchorage in a certain kind of artistic ethos at a very early point in his life. Abstract painting came to prominence in Bangladesh in the 1960s but gradually subsided in the following decades as most of its famed practitioners increasingly moved towards semi-abstract, figurative and other representational practices; subsequently prioritizing them in the emerging visual idioms of new Bangladesh over nonrepresentational practices like abstract art. What else was common for all the four is that they had to migrate to East Pakistan following Partition and they also witnessed the making of the nationspirit Bangladesh at the street-level. Though they shared many common experiences, their style and palette were quite different with individual uniqueness and exhibited different ways to approach, interpret and visualize the modern condition. Saifuddin along with Qamrul and others was also instrumental in establishing the Dhaka Art College (now the Institute of Fine Arts, Dhaka University). Through these initiatives, new generations of artists and art-making were inspired. Through the seventies after the death of Sheikh Mujib, Bangladesh witnessed tumultuous changes- growing Islamization and fundamentalism impacted heavily on the practice of the arts in general; this included not only individual artists and intellectuals from urban areas of Dhaka and Chittagong but also the mass village-based craft industries like the Hindu 
community of potters, or the dhakis, the traditional drum players (a living performative tradition) and numerous others engaged with different folk and traditional artistic and cultural activities. Many of the actually faced forced migration at a very late period in the recent history of IndoBangladesh migration, and which continues till today. Though at an apparent level this seems discouraging to the practice of arts, in time it also proved to be a radicalization factor; artistic and aesthetic sensibility of the coming generations thus evolved into something more radical, experience-based and non-conformist- actively re-inventing their styles, to suit the forces of economy and making them meaningful in the context of their shared experiences.

Today, in twenty-first century Bangladesh, Modernism in artistic and cultural practices is vibrantwith numerous young visual artists emerging from every nook and corner of the country; in recent times, it's not just the urban population which shows an interest in the practice of modern arts but even in the remote countryside, new talents emerge who do make it at times, but rather sporadically, to the institutions of eminence from where they get the necessary training and education before they embark upon their careers as artists. Institutional infrastructure for nurturing the practice of the arts is at an all-time-low, not only in Bangladesh, but also in the subcontinent. The outreach of these institutions should be broadened to include the 'region' and not just the capital.

\section{Ghiyasuddin and Japan}

'I am after all a Bangladeshi artist. No doubt my professional years were spent in Japan, but my life's experience is firmly embedded in the Bengali psyche. My compositions are abstract, freely using the signs and symbols I have naturally borrowed from local folk tales and myths, but they are not applied in any traditional sense. I only use them as vehicles for my own emotions. I have used the common designs in embroidered quilts, with floral and bird motifs, but they don't tell stories in my work. I simply want them to convey a momentary mood in the world around us. The face of Bangladesh, with its inimitable eternal charms and endlessly subtle variations, remains at the core of my creative consciousness- Ghiyasuddin' (Falvo 2011).

Poetic inspiration, for him, ranged from the visual idioms of country-life to the vibrant living traditions and philosophy of life as enumerated through rustic simplicity and diversity. The 'momentary mood' is of prime significance in most of his paintings, which re-iterates the privileging of the im-mediate in abstract art. Artistic expression, which Richard Wollheim once located at the intersection between 'externalization' and 'projection', becomes a site of contestation. One cannot challenge Wollheim when he identifies the need to incorporate perception of both 'externalized' and 'projective' properties into an account of the distinctive variety of expressive perception offered by art. However, he fails to do justice when the comprehension of both kinds of qualities in a work of art is unique to our subjective perceptions of art. There are two traditions by which we might attend to an object- the ordinary 'interested' attention to practical life, and the special 'disinterested' attention with which we can engage with an object in aesthetic contemplation". We take disinterested pleasure in an object when we 'do not have regard for our own interest' and this has slowly and profitably become a condition of modernity and a pillar of late-Capitalist advertising. However, with proper artistic utilization this can become the style of styles- the ultimate 'projective'; abstract art exploits this and Ghiyasuddin mastered it.

Artistic consciousness in both the Bengals has always been superbly rich in visual idioms. This is the same tradition to which Ghiyasuddin also belongs but belongs differently. According to Irving 
Zupnick- "there are three generic perspectives in modern abstract art"- the first that perceives life as an unstable structure of constant change (kinesthesia), the second tradition that looks out for "Platonic universality of form by saturating surface particularities while the third is connected with the uncertainty of the objective realm" in which outside appearances or face-value overwhelmingly conceals intrinsic value. (Zupnick 1965). Ghiyasuddin as an artist has no attachment for this 'uncertain objective realm' but yet he represents it without imitating. It is Bangladesh, the modern-day Bangladesh of urban horrors, traffic jams and climate change and also the rustic hinterland which may appear exceptionally beautiful and serene but even where in the village societies in the process of tryst with modernity, everything has come over to the same dynamic fold, and beings of the human being everywhere is in misery, peril and always at odds with society, the same society which woman/man herself/himself made for her/his own welfare, he/she now has to fight it and rebel against it. Bangladesh is no exception, fighting its own shadow with poverty and unemployment; human exploitation for profit being visible everywhere. The interaction of Indian and Japanese arts is not new in the rich history of the subcontinent's and Japan's cultural exchange. Japanese art itself has been traditionally open to new forms and styles. Shantiniketan and the Bengal School opened the possibilities of artistic interactions to new dimensions and Japanese artists and art practices have inspired generations of the subcontinent's artists. But still for the young Ghiyasuddin, with fresh memories of ' 71 and what followed, Japan was another world. While still studying at Chittagong University, after moving from Dhaka he got the opportunity to travel to and study in Japan and this proved to be 'the' artistic opportunity of his lifetime not only for himself but he would also prove to be heavily influential in Japan's domestic art scenario in the coming days. Japanese art which has a long history of foreign associations and assimilations, has always been constructing and deconstructing itself and in the process rebuilding its fundamental reference points and structure and then emerging with a more resolute aesthetic sensibility. Ghiyasuddin ventured to fearlessly apply his own Bengali aesthetic consciousness and experience to the 'proud' tradition of beauty and aesthetic sensibility in Japan. Though he definitely has had his hard times too, today he is no longer a 'foreigner' in Japan. This can be observed in the following critical perspective - 'his aesthetic could be described as the beauty of dreams, or at least an imaginary world that emerges from a fusion of Bangladeshi consciousness and Japanese sensations ... Our chaotic world, full of dream-like flashes, is aptly conveyed by this adopted son from Bangladesh (Yonekura)' (Falvo 2011). This brings us to the question of the kind of 'global' that we are moving towards. Globalization and global identity is ultimately an array of signs, a specific coding with a specific meaning which may seem to be distant and alien vis-à-vis the 'meaninglessness' of an abstract work of art. The 'fiction of national history' has also been for Bangladesh a problematic discourse. In order to maintain distinction from West Bengal, modern Bangladesh's historiography has been largely based on rejection of the Hindu traditions and coming up with an own Bangladeshi identity, but even this, though very much radical did not survive as 'the' ideology and instead became a hotbed of confusions and attempts towards definitions and negotiations of identity. One may also contemplate the representation of the formless through a form, which is a dominating idea in Ghiyasuddin's psyche and also in the Japanese Idealist ${ }^{\mathrm{vi}}$ tradition. Taking out the discourses of globalization and cultural exchange and the discourse of the individual global artist, in his paintings, what we're left with is Nature. He also introduces different shapes and symbols in his paintings ranging from Bengali alphabets (reference to linguistic identity) to a child's drawings (painting within a painting). Figure 1 is an abstract take on the cacophony and richness of nature and natural sounds. 
It was titled Sound of Nature I, and was subsequently followed by two sequels Sound of Nature II and III (Figure 2 \& 3). Sound of Nature I is dominated by different hues of green. He plays with perspective by dividing the paper into six squares of unequal proportions, inside which there are hints of bright colours, geometric shapes, criss-crossed lines and circles resembling lunar craters. Some circles are populated by smaller circles inside. Colour and line, both are manipulated by Ghiyasuddin in order to give a representation to notions of the pure abstract. Nature in its immensity of living force, expressed through multi-layered ambient sound, finds an expression in the visual medium through this painting.

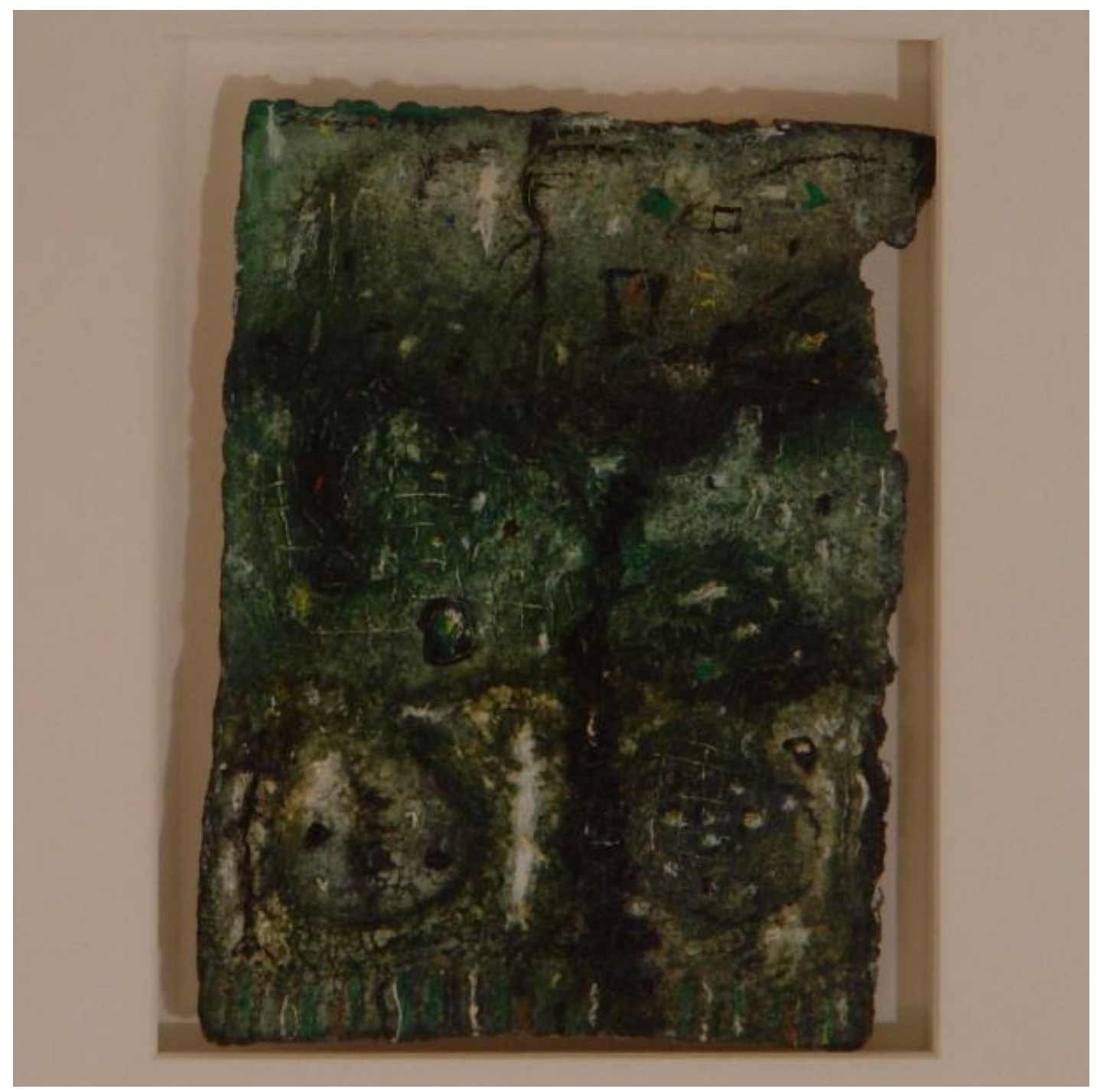

Figure 1: Sound of Nature I, watercolour on paper, $10 \times 8$ in., Ashok Jain Gallery. Image courtesy: Bengal Foundation, Dhaka.

Sound of Nature II is further richer in non-representational content. It features a complete departure from form and shape- signifying the loss of individual subjective consciousness in the context of a reaffirmation between the objective world and the estranged subject. Splashes, 
spillage and dripping have been carefully employed to bring out the visceral and permeable nature of artistic subjectivity. Simple lines, devoid of any coherence are to be found throughout the painting which may be read as fractures in the context of the modern condition. Geometric shapes punctuate the rhetoric of colour, and child's drawing again becomes a recurrent motif- this time, expressing cosmic symbols like the sun and the moon- which may point to the universal nature of the abstract or of locating the abstract as one of the first, primordial and simplest language of expression.

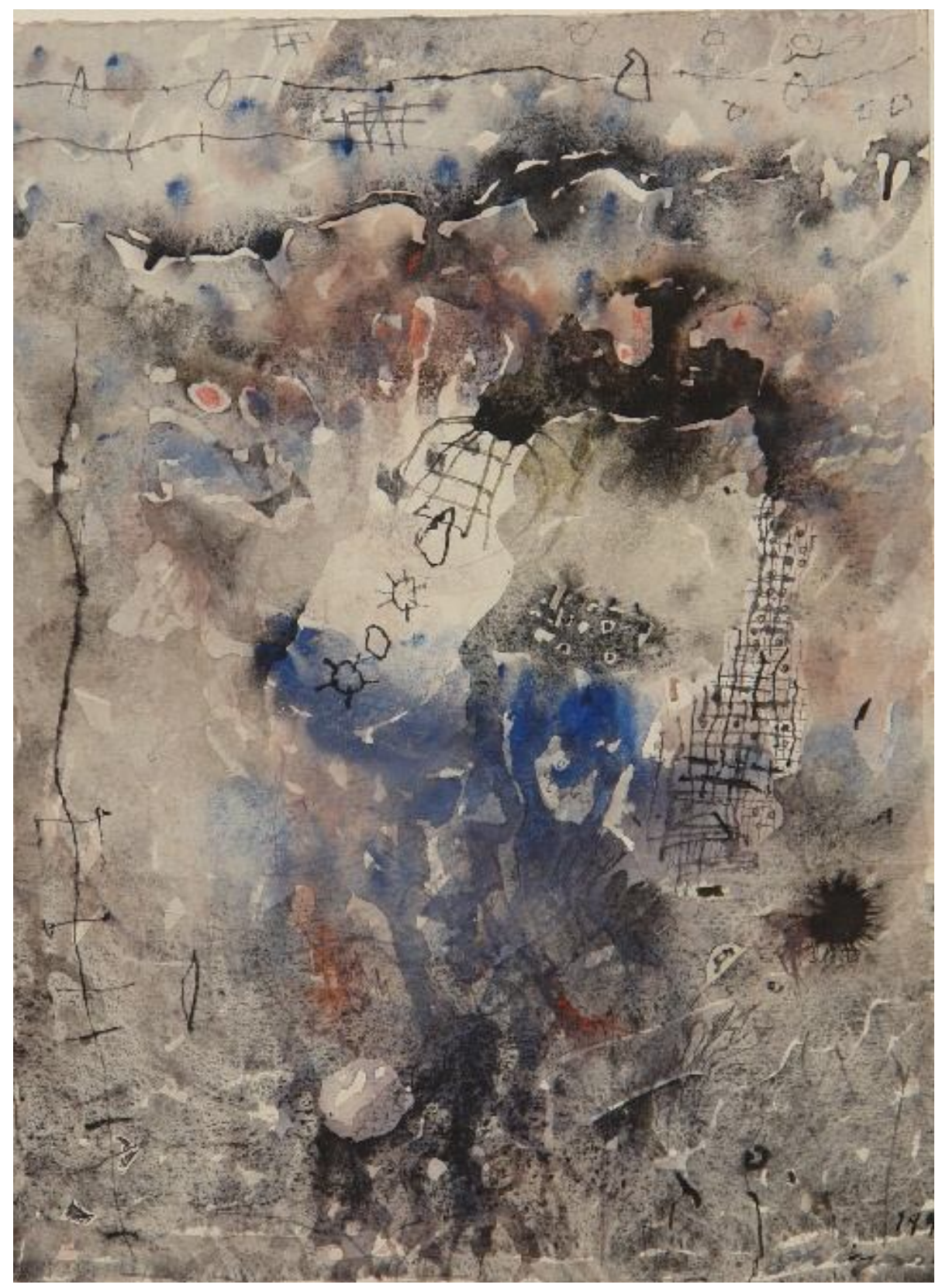

Figure 2: Sound of Nature II, watercolour on paper, $15 \mathrm{x} 11$ in., Ashok Jain Gallery. Image courtesy: Bengal Foundation, Dhaka.

Sound of Nature III is dominated mostly by shades of blue and brown. Lines arranged in crisscross manner at the bottom of the painting problematizes texture, which may signify the context of 
artistic conception. Small two-dimensional triangular hills worked out mostly through line are the first 'figurative' representations that fixes our vision in this painting. Global polarity (as expressed through a compass), also readable as the binary of the medium and the message, might be one of the underlying themes in this painting. But the compass motif recurs in many other of his works as well. On the right half of the painting, we also notice small circles arranged and held in lines over each other. At first glance, this may look like a Chinese abacus. If it is read as an abacus, then it may be interpreted as the only sign of reason and rationality, in this work of art, which otherwise stands for as a representation of the irrational, non-structured nature of our beings. Even in Japan, what truly bonded with the spirit of Ghiyas was the bountiful nature. Hailing from the land of Jibanananda Das, having a weakness for nature only strengthened his artistic sensibility in a professional life in Japan. His abstract form equips his paintings with synesthetic qualities and so the title Sound of Nature is very apt.

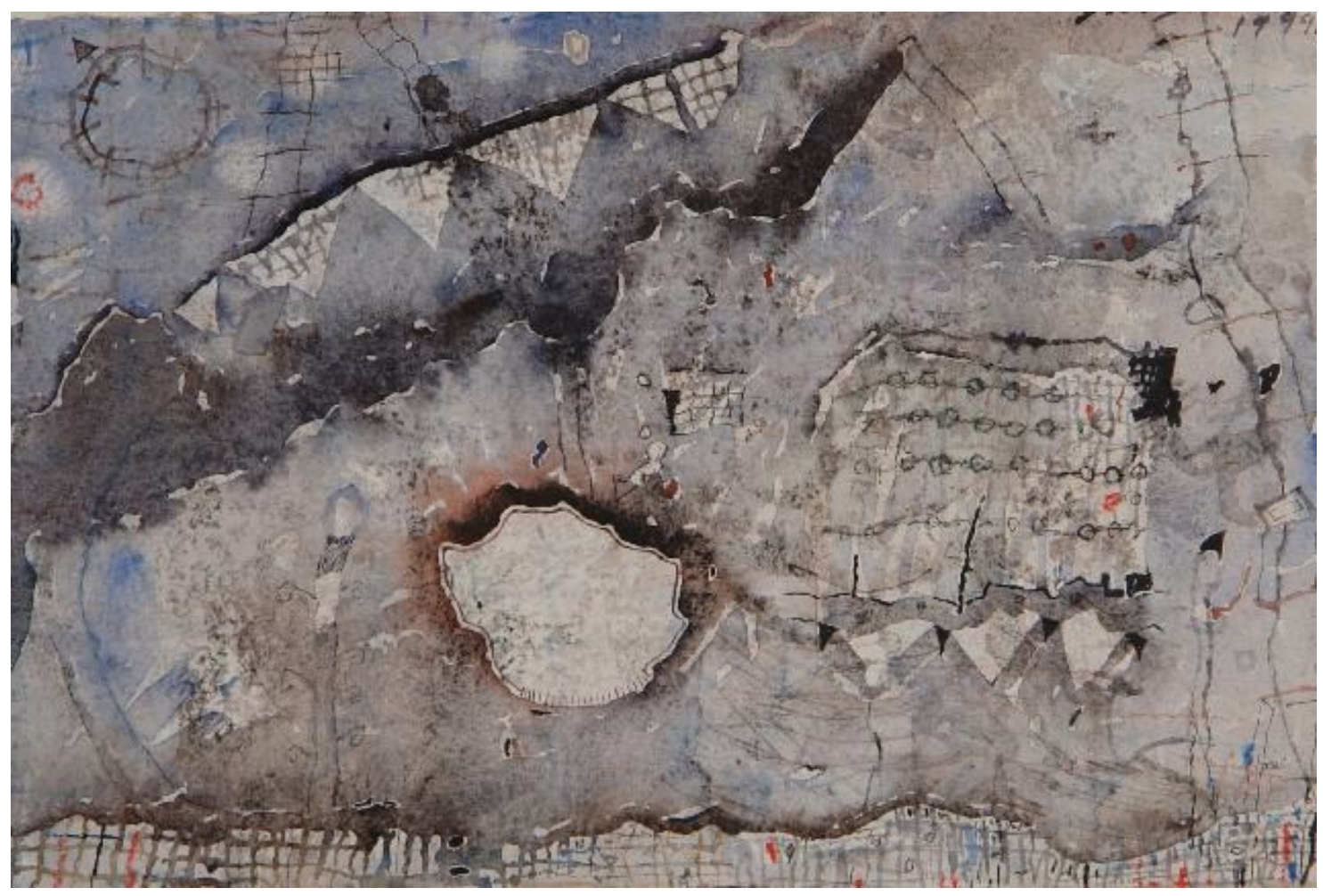

Figure 3: Sound of Nature III, watercolour on paper, 11 x 15 in., Ashok Jain Gallery. Image courtesy: Bengal Foundation, Dhaka.

Figure 4 is titled Around My Studio. It is a departure from the works in watercolour we previously discussed. This also featured as the cover of the publication Contemporary Masters of Bangladesh: Kazi Ghiyasuddin. It is an attempt at an organification of the artist's world and his environment. Artistic subjectivity is again, in dialogue with nature- natural patterns, geometric shapes dominate the canvas and the palette is rich in earthly tones (signifying perhaps the material origin of colour) with occasional splashes of bright colour that may signify emotion or a rupture. Interestingly, this painting in 'oil'- a medium which perhaps most appropriately signifies the professional artist starting from the Renaissance and European modernity, is also reminding of satellite photography of geographical terrains. Desert, craters, arid land, cultivated land (denoted 
by the criss-cross) and spoilt/burnt land (denoted by use of darker colours) and snow can be seen in this assemblage of natural forms. This painting may in a way signify the elemental nature of artistic and creative consciousness. The recluse in nature that he enjoyed in Bangladesh and Japan alike envigored his abstract style. He held his first solo exhibition in Bangladesh in 1970 at the East Pakistan Arts Council, his next solo in Bangladesh was held only in 1993 at the Bangladesh Shilpakala Academy after long gap (when he was in Japan) which points out to the deteriorating conditions of art practice in Bangladesh. Through the form of the abstract, he is perhaps the only artist in Bangladesh whose work cusps in and around nature and thus in such a sense, he is also perhaps the only Romantic abstract artist from Bangladesh. The work Around My Studio has also often been interpreted through the lens of the sublime- "Ghiyas transcends the political world and enters into dialectic of the spirit of art and the spirit of nature" (Quayes 2011) and it is style, his distinctive assimilative individually evolved style which allows him to do so.

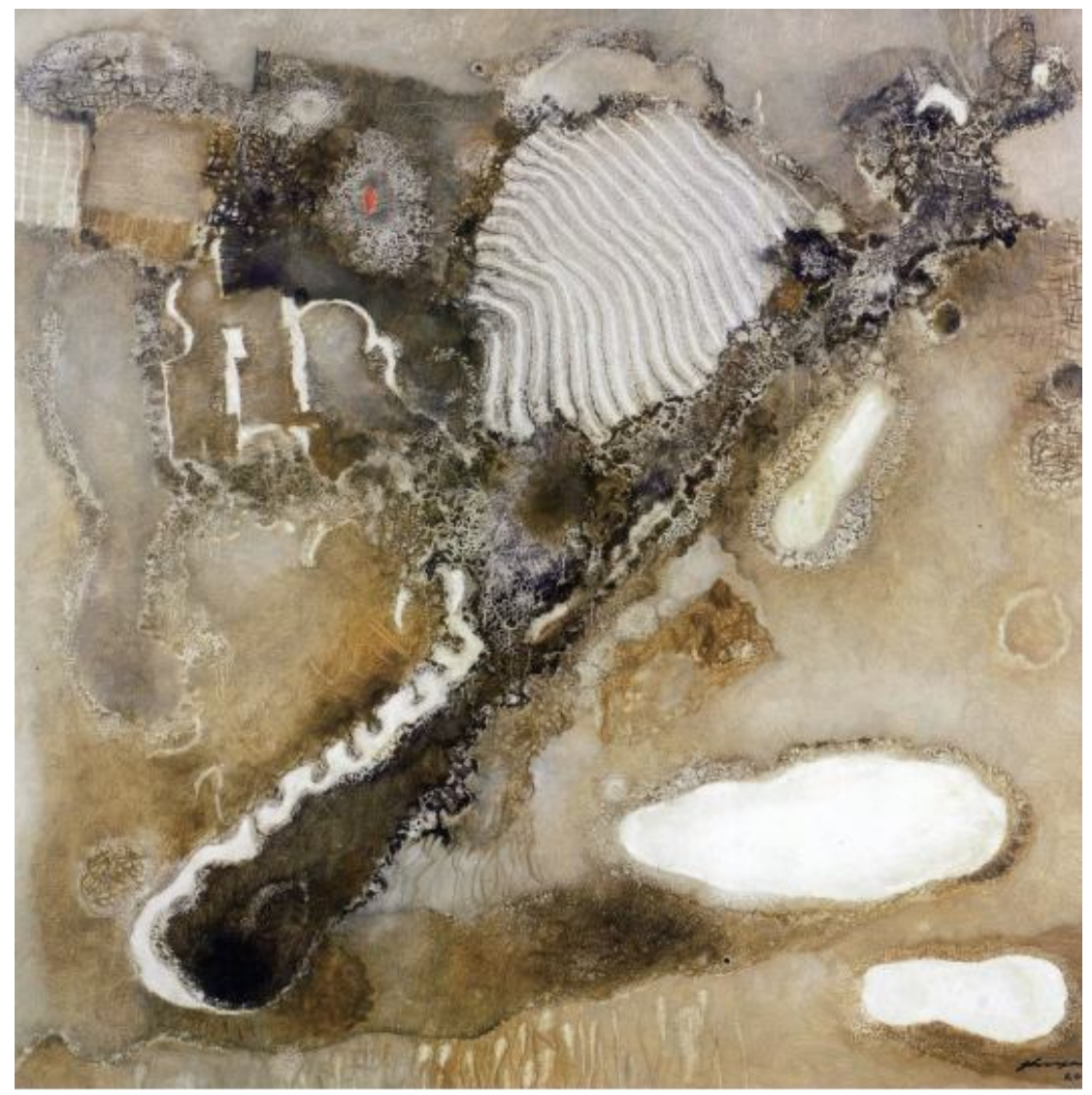

Figure 4: Around my studio, Oil on canvas, Source: http://onbeat.co.jp/en/art/kazi-ghiyasuddin/

Even though today, the abstract remains at the margins of popular expressions of art in Bangladesh and in the subcontinent, in the shadow of the prevalent representational visual idioms and rhetoric, it nonetheless has experienced a steady increase in the number of practitionersmany young artists who have increasingly turned towards the abstract as the appropriate medium of present-day sensibilities and issues, in the context of the human subject, subjective experience, expression and perception. 


\section{Acknowledgements}

Images courtesy: Bengal Foundation, Dhaka.

\section{Notes}

${ }^{\mathrm{i}}$ Nocturne in Black and Gold: The Falling Rocket (1874) was perhaps the first sign of this new art. However, Whistler's other paintings too marks a departure from the sentimentality and moral associations of art as was prevalent at that time; he rather espoused an 'art for art's sake' perspective.

${ }^{\text {ii }}$ For Whistler in the tradition of Ingres and Marc-Charles-Gabriel Gleyre, following academic style, line was more important than colour and black was the fundamental colour of tonal harmony. The Impressionists challenged this, privileging colour over form.

iii Additionally, in the late nineteenth century in eastern Europe, mysticism and early modernist religious philosophy as expressed by theosophist Mme. Blavatsky had a profound impact on pioneer geometric artists like Wassily Kandinsky and Hilma af Klint. The mystical teachings of Georges Gurdjieff and P D Ouspensky also had an important influence on the early formations of the geometric abstract styles of Piet Mondrian and his colleagues in the early twentieth century. The legacy of geometric abstract is visible in Ghiyasuddin's paintings.

${ }^{\text {iv }}$ Only in his 2004 exhibition at the Miyuki Gallery in Ginza, did he choose two-thirds of the twenty-one selections to be oil-paint. "Visitors who saw his 2001 and 2002 exhibitions of watercolour in Tokyo, including one at Miyuki, may feel a sense of deja-vu' reported the Japan Times.

${ }^{v}$ The idea that a subject might attend to an object without having regard for the subject's own interests was reintroduced into philosophy in the eighteenth century by the third Earl of Shaftesbury, and finds its most sophisticated treatment in Kant's Third Critique, although it remained a persistent approach in the twentieth century.

${ }^{\text {vi }}$ Kitaro Nishida (1850-1945) who famously declared- 'an object without a form can be expressed by one with a form.'

\section{References}

Falvo, R.M. (2011). ed. Contemporary Masters of Bangladesh: Kazi Ghiyasuddin. Milano: Skira.

James, V. (2004). "A Colorful Realm of the Senses." In The Japan Times (Tokyo), May 05, Culture section.

Quayes, M.M. (2011). "Sojourn into the Sublime." In Contemporary Masters of Bangladesh: Kazi Ghiyasuddin. Milan: Skira Editore.

Said, E.W. (2006). In On Late Style: Music and Literature against the Grain. New York: Pantheon Books.

Selim, L.R. (2014). "Art of Bangladesh: the Changing Role of Tradition, Search for Identity and Globalization". South Asia Multidisciplinary Academic Journal [Online] (Association pour la Recherche sur l'Asie du Sud) (9): 10-19. Archived from the original on 4 August 2014. Retrieved 28 July 2014. Used $05^{\text {th }}$ February, 2019.

Zupnick, I. (1965). "Philosophical Parallels to Abstract Art". In The Journal of Aesthetics and Art Criticism, 23(4), 473-479. doi:10.2307/427669 